\title{
Pregnancy Increases Norbuprenorphine Clearance in Mice by Induction of Hepatic Glucuronidation
}

\author{
Michael Z. Liao, Chunying Gao, Brian R. Phillips, Naveen K. Neradugomma, Lyrialle W. Han, \\ Deepak Kumar Bhatt, Bhagwat Prasad, Danny D. Shen, and Qingcheng Mao
}

Department of Pharmaceutics, School of Pharmacy, University of Washington, Seattle, Washington

Received May 5, 2017; accepted November 17, 2017

\begin{abstract}
Norbuprenorphine (NBUP) is the major active metabolite of buprenorphine (BUP) that is commonly used to treat opiate addiction during pregnancy; it possesses $25 \%$ of BUP's analgesic activity and 10 times BUP's respiratory depression effect. To optimize BUP's dosing regimen during pregnancy with better efficacy and safety, it is important to understand how pregnancy affects NBUP disposition. In this study, we examined the pharmacokinetics of NBUP in pregnant and nonpregnant mice by administering the same amount of NBUP through retro-orbital injection. We demonstrated that the systemic clearance (CL) of NBUP in pregnant mice increased $\sim 2.5$-fold compared with nonpregnant mice. Intrinsic CL of NBUP by glucuronidation in mouse liver microsomes from pregnant mice was $\sim 2$ times greater than that from nonpregnant mice. Targeted liquid chromatography tandem-mass spectrometry
\end{abstract}

proteomics quantification revealed that hepatic Ugt1a1 and Ugt2b1 protein levels in the same amount of total liver membrane proteins were significantly increased by $\sim 50 \%$ in pregnant mice versus nonpregnant mice. After scaling to the whole liver with consideration of the increase in liver protein content and liver weight, we found that the amounts of Ugt1a1, Ugt1a10, Ugt2b1, and Ugt2b35 protein in the whole liver of pregnant mice were significantly increased 2 -fold compared with nonpregnant mice. These data suggest that the increased systemic CL of NBUP in pregnant mice is likely caused by an induction of hepatic Ugt expression and activity. The data provide a basis for further mechanistic analysis of pregnancy-induced changes in the disposition of NBUP and drugs that are predominately and extensively metabolized by Ugts.

\section{Introduction}

Opioid addiction cases in the United States continue to escalate as a top national health crisis. Opioid addiction as a result of prescription opioid use during pregnancy accounted for $28 \%$ of admissions of pregnant women to treatments of drug abuse from 1992 to 2012 (Martin et al., 2015). Untreated substance abuse during pregnancy increases the risk for adverse pregnancy outcomes and fetal anomalies. Due to the dual risk to the mother and fetus, opioid addiction treatment is an increasing priority for this understudied population. Although methadone as a medication-assisted treatment of opioid addiction is the gold standard, recent research supports the use of buprenorphine (BUP) for opioid treatment during pregnancy. Randomized clinical trials comparing methadone and BUP indicate that both medications are effective in preventing relapse in opioiddependent patients (Stotts et al., 2009). Moreover, increasing clinical research suggests that the use of BUP results in more favorable maternal and fetal outcome (shorter hospital stay, shorter duration of treatment of neonatal abstinence syndrome) compared with methadone (Jones et al., 2010).

This work was supported by the National Institutes of Health [Grant DA032507] and the National Center for Advancing Translational Sciences of the NIH [Grant TL1TR000422].

https://doi.org/10.1124/dmd.117.076745.
BUP (Fig. 1) is a semisynthetic $\mu$-opioid receptor agonist and $\kappa$-opioid and $\delta$-opioid receptor antagonist. BUP is metabolized by cytochrome $\mathrm{P} 4503 \mathrm{~A}$ through $\mathrm{N}$-dealkylation to norbuprenorphine (NBUP) (Fig. 1). NBUP is the major active metabolite of BUP in humans and rodents with $\sim 25 \%$ of BUP's intrinsic analgesic activity (Brown et al., 2012). Both BUP and NBUP can be further metabolized primarily to buprenorphine-3- $\beta$-D-glucuronide and norbuprenorphine3- $\beta$-D-glucuronide (NBUP-G, Fig. 1), respectively, by uridine 5' diphospho-glucuronosyltransferases (UGTs) (Brown et al., 2011). A mass balance study on BUP revealed that NBUP and NBUP-G exposure accounted for $>10 \%$ of the total BUP plasma exposure (Jones, 1997). As per US Food and Drug Administration Safety Testing of Drug Metabolite Guidance for Industry, human metabolites formed at $>10 \%$ of total drug-related exposure at steady state could raise safety concerns (US Food and Drug Administration, 2016). Given the fact that NBUP can produce respiratory depression 10 times more potent than BUP in rodents (Yassen et al., 2007) and possibly in infants (Kim et al., 2012), drug-drug interactions with BUP leading to elevated systemic concentrations of NBUP may contribute to an increased risk of neurorespiratory depression. Therefore, to optimize BUP's dosing regimen with better efficacy and safety, we need to understand the disposition and pharmacokinetics (PK) of not only BUP but also NBUP. Although the disposition of BUP has been extensively studied (Hand et al., 1990; Chiang and Hawks, 2003; Kacinko et al., 2008) and the dose-normalized plasma AUC of BUP has been shown to be significantly decreased about

ABBREVIATIONS: AUC, area under plasma concentration-time curve; BUP, buprenorphine; $\mathrm{CL}$, clearance; $\mathrm{CL}_{\text {int }}$, intrinsic clearance; EDTA, ethylenediaminetetraacetic acid; gd, gestation day; LC-MS/MS, liquid chromatography tandem-mass spectrometry; NBUP, norbuprenorphine; NBUP-G, buprenorphine-3- $\beta$-D-glucuronide; PK, pharmacokinetics; UDPGA, UDP-glucuronic acid; UGT/Ugt, uridine 5'-diphospho-glucuronosyltransferases. 

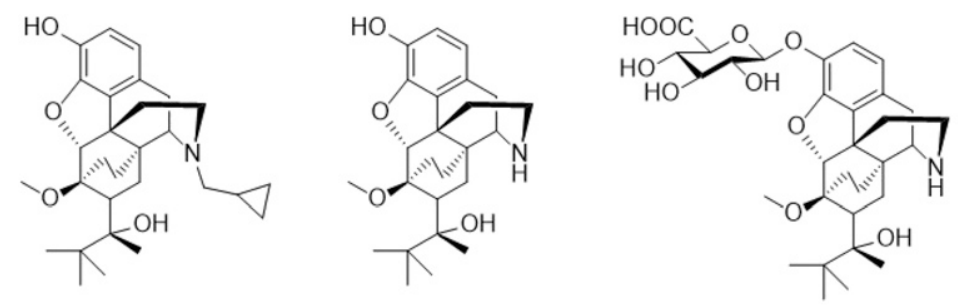

Buprenorphine
Fig. 1. Chemical structures of buprenorphine, norbuprenorphine, and norbuprenorphine-3- $\beta$-D-glucuronide. twofold by pregnancy in pregnant women (Bastian et al., 2017), much less is known about NBUP in this regard, particularly during pregnancy. Pregnancy causes drastic changes in hormone production, such as elevated levels of estrogens, progesterone, cortisol, and growth hormones, which may be responsible for altered expression and activity of drug metabolizing enzymes (Anderson, 2005). As a result, some UGTs may be upregulated by pregnancy (Jeong et al., 2008; Chen et al., 2009; Wen et al., 2013). Given that NBUP is extensively metabolized by UGTs (Chang and Moody, 2009; Rouguieg et al., 2010), whether the disposition of NBUP is altered by pregnancy due to induction of glucuronidation warrants investigation. No such studies have been reported so far.

Therefore, in this study, we first determined the PK of NBUP and NBUP-G in pregnant and nonpregnant mice. We then demonstrated whether the intrinsic clearance of NBUP by glucuronidation and Ugt protein expression in the mouse liver were increased by pregnancy. The data obtained will facilitate mechanistic understanding of changes in the disposition of NBUP during pregnancy, which could be important to inform therapeutic strategies in pregnant women for BUP and drugs that are primarily metabolized by UGTs.

\section{Materials and Methods}

Materials. NBUP and NBUP-G used for animal studies were provided by the National Institute on Drug Abuse (Bethesda, MD). NBUP, norbuprenorphine-d3 (NBUP-d3), and NBUP-G used for analytical calibrations in LC-MS/MS assays were from Cerilliant (Round Rock, TX). Optima grade or high-performance liquid chromatography grade methanol, acetonitrile, polyethylene glycol 400, ethanol, formic acid, dimethyl sulfoxide, and water were from Thermo Fisher Scientific (Waltham, MA) or Acros Organics (Pittsburgh, PA). Isoflurane was purchased from Piramal Healthcare (Mumbai, India) through the University of Washington Medical Center Pharmacy. UDP-glucuronic acid (UDPGA) and alamethicin (from Trichoderma viride) were purchased from Sigma-Aldrich (St. Louis, MO). Synthetic signature peptides for LC-MS/MS protein quantification were obtained from New England Peptides (Boston, MA). The corresponding stable-isotope-labeled peptides were from Thermo Fisher Scientific (Rockford, IL). The ProteoExtract native membrane protein extraction kit was from Calbiochem (Temecula, CA). Ammonium bicarbonate and sodium deoxycholate were from Thermo Fisher Scientific and MP Biomedicals (Santa Ana, CA), respectively. BCA protein assay and in-solution trypsin digestion kits, iodoacetamide, and dithiothreitol were obtained from Pierce Biotechnology (Rockford, IL).

Animal Studies. This animal protocol was approved by the Institutional Animal Care and Use Committee of the University of Washington. Wild-type FVB mice, 7-10 weeks of age, were purchased from Taconic Farms (Germantown, NY) and cared for in accordance with the Guide for the Care and Use of Laboratory Animals published by the National Research Council. Mice were maintained under 12-hour light/dark cycles, and food and water were provided ad libitum. Female mice were mated with male mice of the same age overnight using a female to male ratio of 2:1. Gestation day (gd) 1 was defined as the presence of a sperm plug following overnight housing. Increase in body weight was used as an indicator for healthy pregnancy. Body weight was recorded on the day of dosing. Pregnant mice used in this study were on gd 15, which approximately corresponds to the late second trimester in humans. Nonpregnant female mice were compared with pregnant mice throughout this study with respect to the PK of NBUP and its derived glucuronidated metabolite NBUP-G.

The animal study protocol was essentially the same as previously described (Liao et al., 2017). Briefly, NBUP was dissolved in a solution that contained $0.5 \%$ $(\mathrm{v} / \mathrm{v})$ dimethyl sulfoxide, $10 \%(\mathrm{v} / \mathrm{v})$ ethanol, $39.5 \%(\mathrm{v} / \mathrm{v})$ saline, and $50 \%(\mathrm{v} / \mathrm{v})$ polyethylene glycol 400 at a concentration of $0.5 \mathrm{mg} / \mathrm{ml}$. Under $2 \%-5 \%$ isoflurane anesthesia, each pregnant or nonpregnant mouse was administered the same dose of $33 \mu \mathrm{g}$ of NBUP by retro-orbital injection. This dose was selected based on literature data about elicitation of a significant decrease in respiratory rate in mice and the achievement of plasma concentration of NBUP in mice (Brown et al., 2012) that was comparable to that observed in pregnant women in the late second and early third trimesters (Concheiro et al., 2011). Previous pharmacokinetic studies showed that the half-life of NBUP in rodents was approximately 0.9 hours (Ohtani et al., 1994). We therefore administered NBUP to pregnant and nonpregnant female mice and collected blood at time points up to 720 minutes, which is longer than 10 half-lives. Thus, at various times $(2,30,120$, 240, 480, and 720 minutes) after NBUP administration, mice ( $n=3 /$ time point) were euthanized under anesthesia by cardiac puncture. Blood samples were collected in heparinized microcentrifuge tubes (BD Bioscience, San Jose, CA) and centrifuged at $1000 \mathrm{~g}$ for 10 minutes at $4^{\circ} \mathrm{C}$. Plasma was collected and stored at $-80^{\circ} \mathrm{C}$ until use. At the first two time points, blood samples were collected under the same anesthetic used for the NBUP administration. Liver tissues were collected at the same time points as blood samples. NBUP and NBUP-G in plasma samples were quantified by a validated LC-MS/MS assay as previously described (Liao et al., 2017).

Plasma Protein Binding of NBUP. Protein binding of NBUP in mouse plasma was determined by ultrafiltration using Microcon-10 kDa Centrifugal Filter with Ultracel-10 membranes (EMD Millipore Corporation, Billerica, MA) at $\sim 1 \mu \mathrm{M}$, which is the $C_{\max }$ of NBUP in pregnant mice determined in this study. Plasma protein binding by ultrafiltration method was performed as previously described (Shuster et al., 2014). Briefly, NBUP in methanol was aliquoted into $1.5 \mathrm{ml}$ Eppendorf tubes and evaporated to dryness. Plasma from pregnant or nonpregnant mice ( $\mathrm{gd} 15$ ) was added to each tube to a total volume of $220 \mu \mathrm{l}$. Samples were briefly vortexed and allowed to equilibrate for 30 minutes at $37^{\circ} \mathrm{C}$. Two 100- $\mu$ l aliquots from each sample were transferred to ultrafiltration cartridges, equilibrated for 30 minutes at $37^{\circ} \mathrm{C}$, and centrifuged at $1000 \mathrm{~g}$ for 20 minutes. NBUP in $3 \mu \mathrm{l}$ of filtrate and unfiltered plasma was quantified by LC-MS/MS as previously described (Liao et al., 2017). The fraction unbound of NBUP was calculated as the percentage of the concentration of NBUP in filtrate to the concentration of NBUP in corresponding unfiltered plasma. This plasma protein binding study was repeated with six independent experiments with each done in in triplicate.

NBUP-G Formation Kinetics in Mouse Liver Microsomes from Pregnant and Nonpregnant Mice. Microsomes were prepared from mouse liver tissues isolated from pregnant and nonpregnant mice as previously described (Shuster et al., 2014). Briefly, every $1 \mathrm{~g}$ of mouse liver tissue was homogenized in $3 \mathrm{ml}$ of homogenization buffer (50 mM KPi buffer containing $0.25 \mathrm{M}$ sucrose and $1 \mathrm{mM}$ EDTA) using an Omni Bead Ruptor Homogenizer (Omni International). The homogenate was centrifuged at $15,000 \mathrm{~g}$ for 30 minutes at $4^{\circ} \mathrm{C}$, and the supernatant was centrifuged at $120,000 \mathrm{~g}$ for 70 minutes at $4^{\circ} \mathrm{C}$. Microsomal pellets were resuspended in the washing buffer $(10 \mathrm{mM} \mathrm{KPi}, 0.1 \mathrm{mM} \mathrm{KCl}$, and $1 \mathrm{mM}$ EDTA, pH 7.4) and then centrifuged at $120,000 \mathrm{~g}$ for 70 minutes at $4^{\circ} \mathrm{C}$. Microsomal pellets were finally resuspended in $1 \mathrm{ml}$ of storage buffer $(50 \mathrm{mM}$ $\mathrm{KPi}, 0.25 \mathrm{M}$ sucrose, and $10 \mathrm{mM}$ EDTA, $\mathrm{pH}$ 7.4) and stored at $-80^{\circ} \mathrm{C}$ until use. Microsomal protein concentrations were determined using the BCA protein assay. 
NBUP-G formation kinetics were determined with substrate (NBUP) concentrations up to $400 \mu \mathrm{M}$. Microsomes were diluted to a final concentration of $1 \mathrm{mg} / \mathrm{ml}$ of protein in $100 \mu \mathrm{l}$ of $0.1 \mathrm{M}$ Tris/HCl buffer (pH 7.4) containing $8 \mathrm{mM}$ $\mathrm{MgCl}_{2}$. The microsomes were activated by adding alamethicin at a concentration of $25 \mu \mathrm{g} / \mathrm{mg}$ microsomal protein and left on ice for 15 minutes. The NBUP solutions and microsomes were then mixed and preincubated for 5 minutes at $37^{\circ} \mathrm{C}$, and the reaction was initiated by adding $2 \mathrm{mM}$ UDPGA. Concentrations of NBUP used in the microsome incubations were selected based on the $K_{\mathrm{m}}$ value $(\sim 144 \mu \mathrm{M})$ of UGTs for NBUP (Chang and Moody, 2009). Incubations without UDPGA were used as negative controls. Our preliminarily experiments indicated that the NBUP-G formation was linear up to 10 minutes. Therefore, an incubation time of 10 minutes was used for all subsequent microsome incubations. All reactions were stopped by the addition of $100 \mu \mathrm{l}$ of ice-cold methanol. The kinetic experiments were repeated independently three times, each with triplicate determinations at each substrate concentration. After the addition of $20 \mu \mathrm{l}$ NBUP- $\mathrm{d}_{3}$ (internal standard, $5 \mathrm{ng} / \mu \mathrm{l}$ ), samples were briefly vortexed and centrifuged at $20,800 \mathrm{~g}$ for 10 minutes at $4^{\circ} \mathrm{C}$. The supernatant was transferred to a 96-well plate and subjected to LC-MS/MS as previously described (Liao et al., 2017) and NBUP-G was quantified. $K_{\mathrm{m}}$ and $V_{\max }$ of NBUP-G formation kinetics were estimated by fitting the Michaelis-Menten equation to the experimental data with nonlinear regression using the GraphPad Prism software
(GraphPad Prism 5.01, La Jolla, CA). The intrinsic clearance $\mathrm{CL}_{\text {int }}$ was calculated by dividing the $V_{\max }$ by the $K_{\mathrm{m}}\left(V_{\max } / K_{\mathrm{m}}\right)$.

Protein Quantification of Ugts in Pregnant and Nonpregnant Mouse Livers by LC-MS/MS. Protein quantification of murine Ugt isoforms (Ugt1a1, Ugt1a6, Ugt1a8, Ugt1a10, Ugt2b1, and Ugt2b35) in pregnant and nonpregnant mouse livers was carried out using a surrogate peptide-based LC-MS/MS method as previously described (Prasad et al., 2014). One or two signature peptides unique for the Ugt isoforms (Table 1) were selected for quantification of each enzyme based on previously reported criteria (Prasad et al., 2014). The corresponding heavy peptides containing labeled $\left[{ }^{13} \mathrm{C}_{6}{ }^{15} \mathrm{~N}_{2}\right]$-lysine or $\left[{ }^{13} \mathrm{C}_{6}{ }^{15} \mathrm{~N}_{4}\right]$-arginine were used as internal standards (Table 1). Prior to protein quantification, liver tissues from pregnant and nonpregnant mice were homogenized in extraction buffer I of the ProteoExtract native membrane protein extraction kit containing protease inhibitor cocktail according to the manufacturer's instruction. The resulting homogenate was centrifuged at 16,000 $g$ for 15 minutes and the supernatant was discarded. The pellet was resuspended in $1 \mathrm{ml}$ of extraction buffer II with protease inhibitor cocktail and incubated with gentle shaking for 30 minutes at $4^{\circ} \mathrm{C}$, followed by centrifugation at $16,000 \mathrm{~g}$ for 15 minutes at $4^{\circ} \mathrm{C}$. The concentration of total isolated membrane proteins in the supernatant was then determined using the BCA protein assay. The supernatant was diluted to protein concentration of $2 \mu \mathrm{g} / \mu \mathrm{l}$. The total membrane proteins were reduced, denatured, alkylated, desalted, and

TABLE 1

Surrogate peptides of Ugts and their MS/MS parameters

\begin{tabular}{|c|c|c|c|c|c|c|}
\hline Protein Name & Surrogate Peptide & Peptide Type & $\begin{array}{c}\text { Parent Ion } \\
(\mathrm{m} / \mathrm{z})\end{array}$ & $\begin{array}{l}\text { Fragment Ion } \\
\qquad(\mathrm{m} / \mathrm{z})\end{array}$ & Declustering Potential(V) & Collision Energy(V) \\
\hline Ugtla1 & EGSFYTLR & Light & 486.743 & 699.382 & 66.6 & 26.4 \\
\hline Ugtla1 & EGSFYTLR & Light & 486.743 & 552.314 & 66.6 & 26.4 \\
\hline Ugt1a1 & EGSFYTLR & Heavy & 491.747 & 796.423 & 66.6 & 26.4 \\
\hline Ugtla1 & EGSFYTLR & Heavy & 491.747 & 709.391 & 66.6 & 26.4 \\
\hline Ugtla1 & EGSFYTLR & Heavy & 491.747 & 562.322 & 66.6 & 26.4 \\
\hline Ugt1a1 & TAFNQDSFLLR & Light & 656.338 & 992.516 & 79 & 32.5 \\
\hline Ugtla1 & TAFNQDSFLLR & Light & 656.338 & 878.473 & 79 & 32.5 \\
\hline Ugtla1 & TAFNQDSFLLR & Light & 656.338 & 750.414 & 79 & 32.5 \\
\hline Ugtla1 & TAFNQDSFLLR & Heavy & 661.342 & 888.481 & 79 & 32.5 \\
\hline Ugtla1 & TAFNQDSFLLR & Heavy & 661.342 & 562.262 & 79 & 32.5 \\
\hline Ugtla6 & DSATLSFLR & Light & 505.269 & 736.435 & 68 & 27 \\
\hline Ugtla6 & DSATLSFLR & Light & 505.269 & 635.388 & 68 & 27 \\
\hline Ugtla6 & DSATLSFLR & Light & 505.269 & 522.303 & 68 & 27 \\
\hline Ugt1a6 & DSATLSFLR & Heavy & 510.273 & 746.443 & 68 & 27 \\
\hline Ugtla6 & DSATLSFLR & Heavy & 510.273 & 645.396 & 68 & 27 \\
\hline Ugtla6 & DSATLSFLR & Heavy & 510.273 & 532.312 & 68 & 27 \\
\hline Ugt1a8 & LVEYLK & Light & 382.731 & 651.371 & 59 & 22.6 \\
\hline Ugt1a8 & LVEYLK & Light & 382.731 & 552.303 & 59 & 22.6 \\
\hline Ugtla8 & LVEYLK & Light & 382.731 & 423.26 & 59 & 22.6 \\
\hline Ugt1a8 & LVEYLK & Heavy & 386.738 & 560.317 & 59 & 22.6 \\
\hline Ugt1a8 & LVEYLK & Heavy & 386.738 & 431.274 & 59 & 22.6 \\
\hline Ugtla8 & IPQTVLWR & Light & 506.801 & 899.51 & 68.1 & 27.1 \\
\hline Ugt1a8 & IPQTVLWR & Light & 506.801 & 674.398 & 68.1 & 27.1 \\
\hline Ugtla8 & IPQTVLWR & Light & 506.801 & 573.351 & 68.1 & 27.1 \\
\hline Ugt1a8 & IPQTVLWR & Heavy & 511.805 & 812.465 & 68.1 & 27.1 \\
\hline Ugt1a8 & IPQTVLWR & Heavy & 511.805 & 684.407 & 68.1 & 27.1 \\
\hline Ugtla8 & IPQTVLWR & Heavy & 511.805 & 583.359 & 68.1 & 27.1 \\
\hline Ugt1a10 & YTGTRPSNLAK & Light & 604.325 & 785.463 & 75.2 & 30.6 \\
\hline Ugt1a10 & YTGTRPSNLAK & Light & 604.325 & 629.362 & 75.2 & 30.6 \\
\hline Ugt1a10 & YTGTRPSNLAK & Light & 604.325 & 579.289 & 75.2 & 30.6 \\
\hline Ugt1a10 & YTGTRPSNLAK & Heavy & 608.332 & 894.525 & 75.2 & 30.6 \\
\hline Ugtla10 & YTGTRPSNLAK & Heavy & 608.332 & 793.477 & 75.2 & 30.6 \\
\hline Ugt1a10 & YTGTRPSNLAK & Heavy & 608.332 & 637.376 & 75.2 & 30.6 \\
\hline Ugt2b1 & TPLVYSLR & Light & 474.779 & 750.451 & 65.7 & 25.9 \\
\hline Ugt2b1 & TPLVYSLR & Light & 474.779 & 637.367 & 65.7 & 25.9 \\
\hline Ugt2b1 & TPLVYSLR & Light & 474.779 & 538.298 & 65.7 & 25.9 \\
\hline Ugt2b1 & TPLVYSLR & Heavy & 479.783 & 760.459 & 65.7 & 25.9 \\
\hline Ugt2b1 & TPLVYSLR & Heavy & 479.783 & 647.375 & 65.7 & 25.9 \\
\hline Ugt2b1 & TPLVYSLR & Heavy & 479.783 & 548.307 & 65.7 & 25.9 \\
\hline Ugt2b35 & IILDELVQR & Light & 549.83 & 759.4 & 71.2 & 28.7 \\
\hline Ugt2b35 & IILDELVQR & Light & 549.83 & 644.373 & 71.2 & 28.7 \\
\hline Ugt2b35 & IILDELVQR & Light & 549.83 & 515.33 & 71.2 & 28.7 \\
\hline Ugt2b35 & IILDELVQR & Heavy & 554.834 & 769.408 & 71.2 & 28.7 \\
\hline Ugt 2 b35 & IILDELVQR & Heavy & 554.834 & 654.381 & 71.2 & 28.7 \\
\hline Ugt2b35 & IILDELVQR & Heavy & 554.834 & 525.338 & 71.2 & 28.7 \\
\hline
\end{tabular}


digested as per our previously reported protocol (Boberg et al., 2017). Twenty microliters of heavy peptide internal standard cocktail [prepared in acetonitrile: water, 80:20 (v/v) with $0.5 \%$ formic acid] and $10 \mu \mathrm{l}$ of acetonitrile:water 80:20 $(\mathrm{v} / \mathrm{v})$ containing $0.1 \%$ formic acid was added to each sample. After mixing and centrifugation at $4000 \mathrm{~g}\left(4^{\circ} \mathrm{C}\right)$ for 5 minutes, samples were transferred to LC-MS autosampler vials and stored at $-20^{\circ} \mathrm{C}$ until analysis.

The Ugts were quantified using optimized parameters (Table 1) on the AB Sciex Triple Quad 6500 system (Framingham, MA) coupled to Waters Acquity UPLC system, M-Class (Waters, Hertfordshire, UK). The volume for sample injection was $5 \mu \mathrm{l}$ that contained $\sim 10 \mu \mathrm{g}$ of total protein. The UPLC column (Acquity UPLC HSS T3 $1.8 \mu \mathrm{m}, 2.1 \times 100 \mathrm{~mm}$; Waters) with a Security Guard column $\left(\mathrm{C}_{18}, 4 \mathrm{~mm} \times 2.0 \mathrm{~mm}\right)$ from Phenomenex (Torrance, CA) was eluted $(0.3 \mathrm{ml} / \mathrm{min})$ with a gradient mobile phase consisting of water and acetonitrile (with 0.1 formic acid; see below). The mobile phase gradient conditions were $97 \%$ $\mathrm{A}$ (water containing $0.1 \% \mathrm{v} / \mathrm{v}$ formic acid) and $3 \% \mathrm{~B}$ (acetonitrile containing $0.1 \%$ $\mathrm{v} / \mathrm{v}$ formic acid) held for 3 minutes, followed by four steps of linear gradient of mobile phase B of $3 \%-13 \%, 13 \%-25 \%, 25 \%-50 \%$, and $50 \%-80 \%$ over $3-10$, 10-20, 20-24, and 24.1-25 minutes, respectively. This was followed by a washing step using $80 \%$ mobile phase B for 0.9 minute, and re-equilibration for 4.9 minutes. The parent to product ion transitions for the analyte peptides and their respective stable-isotope-labeled peptides were monitored using optimized LC-MS/MS parameters (Table 1) in Electrospray Ionization (ESI) positive ionization mode. For data analysis, peak response of multiple reaction monitoring transition from each peptide was averaged, and the area ratio of analyte peptide versus internal standard peptide was obtained. Relative protein expression of individual Ugt was presented as the peak area ratio of analyte peptide over that of the internal standard peptide and, then the ratio was normalized to the corresponding ratio of respective Ugt in the pooled liver tissue homogenates. Pooled tissue homogenates were pooled individual liver samples from the same experiment. Normalization to internal standard was necessary to reduce variations between sample preparations. Normalization to pooled tissue homogenates was used as batch to batch quality controls. The experiments were repeated with three independent mouse livers from each group (pregnant and nonpregnant mice) with the same amount of total membrane protein for trypsin digestion and LC-MS/MS analysis. Relative expression of individual Ugt in total membrane protein extracts was scaled to the whole liver using the following method: Relative expression of a Ugt isoform in the whole mouse liver = relative protein expression of the Ugt per microgram of total membrane protein used in tryptic digestion $\times$ yield of protein isolation (microgram per gram liver tissue) $\times$ the weight of a whole mouse liver (gram) isolated from respective mouse.

Pharmacokinetic Data Analysis. The area under concentration-time curve $\left(\mathrm{AUC}_{0-\infty}\right.$ ) values of plasma NBUP and NBUP-G were calculated using the linear trapezoidal method for both pregnant and nonpregnant mice. Since plasma concentrations of NBUP at 720 minutes were below the limit of quantification, data at 720 minutes were not used in the AUC calculation. Therefore, $\mathrm{AUC}_{0-\infty}$ was estimated by extrapolating from the time points at 120, 240, and 480 minutes. The AUC from 480 minutes to infinity accounted for less than $15 \%$ of total $\mathrm{AUC}_{0-\infty}$. Because NBUP in plasma was sampled in different animals at each time point (one-point sampling), we performed the PK data analysis using a population-based bootstrap method as previously described previously (Shuster et al., 2014). $\mathrm{AUC}_{0-\infty}$ and clearance (CL) were calculated. CL was calculated by dose divided by $\mathrm{AUC}_{0-\infty}$. The $95 \%$ confidence intervals of the sample distributions were estimated by bootstrapping the concentration-time data for each group with modification (Mager and Goller, 1998). Briefly, concentrationtime data points from each dataset of interest were randomly sampled with replacement using the $\mathrm{R}$ program. This process was repeated 10,000 times to create 10,000 pseudoconcentration-time profiles. The $95 \%$ confidence interval was the range of AUCs that encompassed the 2.5th to the 97.5th percentiles of the sample distribution. For each profile, concentrations at each time point were averaged and the PK parameters were calculated. Confidence intervals of metabolite/parent $\mathrm{AUC}_{0-\infty}$ ratios were also estimated by bootstrapping 10,000 iterations of the paired metabolite to parent AUC ratios.

Statistical Analysis. Quantitative assays were performed in triplicates and repeated at least three times. Data are presented as mean \pm S.D. of three independent experiments. The $95 \%$ confidence intervals around each estimated PK parameters were determined using the nonparametric bootstrap method (Shuster et al., 2014). Two-side $P$ values were calculated using permutation tests with 10,000 replications (Shuster et al., 2014). For comparisons of data in microsome incubations and proteomic studies, statistically significant differences were determined by unpaired Student's $t$-test. Differences with $P$ values of $<0.05$ were considered statistically significant.

\section{Results}

Pregnancy Increased Systemic Clearance of NBUP. To demonstrate how pregnancy affects the disposition of NBUP, NBUP was administered to pregnant (gd 15) and nonpregnant mice by retro-orbital injection with the same dose of NBUP $(33 \mu \mathrm{g})$ to each mouse. Maternal plasma concentrations of NBUP (Fig. 2, A and C) and NBUP-G (Fig. 2, $\mathrm{B}$ and $\mathrm{D}$ ) in pregnant mice were significantly lower than those in nonpregnant mice. As a result, the plasma $\mathrm{AUC}_{0-\infty}$ of $\mathrm{NBUP}$ in pregnant mice was $\sim 2.5$ times lower than that in nonpregnant mice $(P<0.05)$ (Table 2). The corresponding systemic CL of NBUP in pregnant mice was increased $\sim 2.5$-fold compared with that in nonpregnant mice $(P<$ 0.05 ) (Table 2). Likewise, the plasma $\mathrm{AUC}_{0-\infty}$ of NBUP-G significantly decreased $\sim 2.4$-fold in pregnant mice compared with nonpregnant mice (Table 2). The NBUP-G/NBUP $\mathrm{AUC}_{0-\infty}$ ratio and plasma protein binding of NBUP were not significantly affected by pregnancy (Table 2). We noted that the plasma concentrations of NBUP-G, even at early time points (e.g., 2 minutes), were $\sim 10$ times greater than those of the parent compound NBUP in both pregnant and nonpregnant mice (Fig. 2), suggesting that NBUP was rapidly and extensively metabolized to NBUP-G in mice. This finding is in agreement with human studies showing that the maximum plasma concentrations of NBUP-G were 4-10 times higher than those of NBUP or BUP after oral administration of BUP (McCance-Katz et al., 2006). Thus, in both humans and mice, NBUP-G is the major circulating metabolite after administration of either BUP or NBUP.

Pregnancy Increased Hepatic Glucuronidation of NBUP. UGTmediated metabolism is the primary elimination pathway of NBUP (Picard et al., 2005; Chang and Moody, 2009). The significantly increased CL of NBUP in pregnant mice could be the result of increased Ugt- mediated hepatic metabolism of NBUP. To test this hypothesis, NBUP-G formation by glucuronidation in microsomes prepared from pregnant and nonpregnant mouse livers was performed with NBUP at concentrations up to $400 \mu \mathrm{M}$. Figure 3 shows a representative NBUP-G formation kinetic profile with liver microsomes isolated from nonpregnant (Fig. 3A) and pregnant (Fig. 3B) mice. No glucuronidation of NBUP was observed in the absence of UDPGA (data not shown). We found that $K_{\mathrm{m}}$ values of NBUP-G formation in pregnant and nonpregnant mice were not significantly changed $(21.9 \pm 2.5 \mu \mathrm{M}$ with pregnant mice vs. $25.2 \pm 4.5 \mu \mathrm{M}$ with nonpregnant mice); however, the $V_{\max }$ of pregnant mice was significantly increased compared with nonpregnant mice $(3261 \pm 155 \mathrm{pmol} / \mathrm{mg}$ protein per minute vs. $2322 \pm$ $174 \mathrm{pmol} / \mathrm{mg}$ protein per minute) (Fig. 3, A and B). Thus, pregnancy significantly increased the microsomal $\mathrm{CL}_{\text {int }}$ of NBUP-G formation 1.6-fold compared with nonpregnant controls $[150 \pm 21 \mu \mathrm{l} /$ $($ min $\times$ mg protein) vs. $94 \pm 16 \mu \mathrm{l} /(\min \times \operatorname{mg}$ protein)] (Fig. $3 \mathrm{C})$.

Pregnancy Induced Ugt Expression in Mouse Liver Quantified by Proteomic LC-MS/MS. To confirm whether the increased hepatic $\mathrm{CL}_{\text {int }}$ of NBUP by glucuronidation in pregnant mice is due to induction of Ugt expression and which Ugts are induced by pregnancy, six mouse Ugt isoforms (Ugt1a1, Ugt1a6, Ugt1a8, Ugt1a10, Ugt2b1, and Ugt2b35) were selected based upon their homology to human UGT isoforms that have been shown to metabolize NBUP (Mackenzie et al., 2005) and their moderate to high basal expression in female mouse livers (Buckley and Klaassen, 2007). Due to the lack of selective antibodies and probe substrates for individual mouse Ugt isoforms, the use of immunoblotting or measurement of glucuronidation activity to demonstrate pregnancy-induced changes in expression or activity of individual 

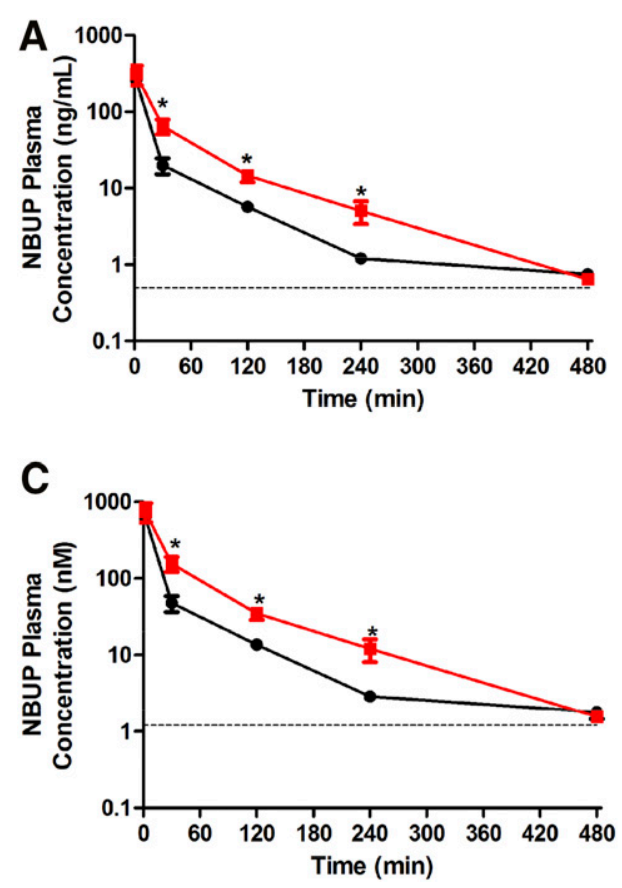
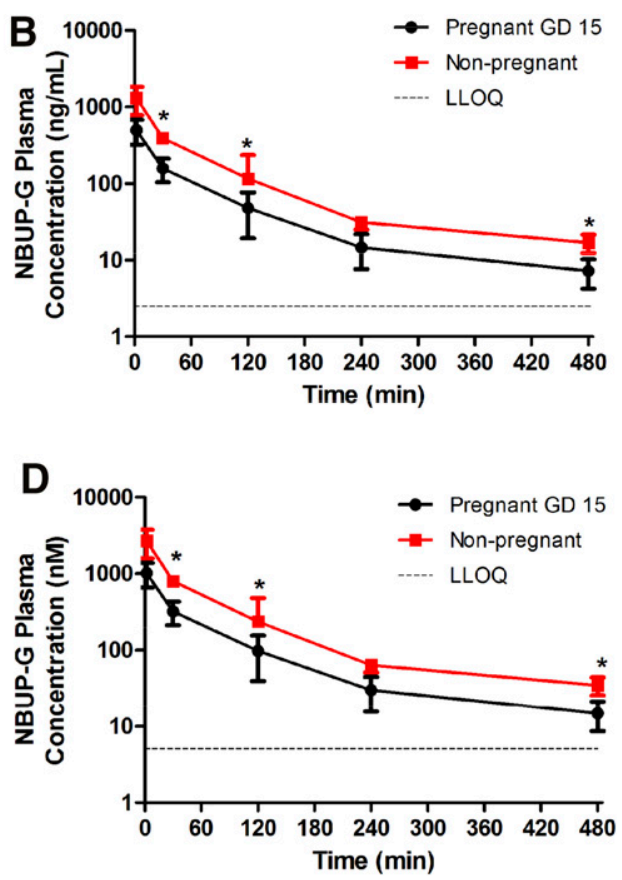

Fig. 2. The plasma concentration-time profiles of norbuprenorphine (NBUP) and norbuprenorphine$3-\beta$-D-glucuronide (NBUP-G) in pregnant and non-pregnant mice. Shown are the plasma concentration concentration-time profiles of NBUP (A) and NBUP-G (B) in nanogram per milliliter concentrations and of NBUP (C) and NBUP-G (D) in nanomolar concentrations, over 480 minutes after retro-orbital injection of $33 \mu \mathrm{g}$ of NBUP to each of pregnant (-) and nonpregnant $(\square)$ mice. Data are shown as means \pm S.D. from three mice at each time point. Statistically significant differences between pregnant and nonpregnant mice were analyzed by the nonparametric bootstrap method, with $P$ values of $<0.05(*)$. Dashed lines represent lower limits of quantification (LLOQ).

mouse Ugts is not feasible. Moreover, LC-MS/MS based proteomics possesses superior accuracy, sensitivity, and reproducibility in quantification of proteins compared with conventional immunoblotting. Since we were primarily interested in pregnancy-induced changes in Ugt expression, only relative (not absolute) hepatic protein expression of individual Ugt isoforms between pregnant and nonpregnant mice was analyzed in this study.

Since $160 \mu \mathrm{g}$ of total membrane proteins were used in each tryptic digestion, the data shown in Fig. 4 demonstrate changes in protein levels of individual Ugts quantified in the same amount of total membrane proteins used in tryptic digestion. Thus, Ugtla1 (Fig. 4A) and Ugt2b1 (Fig. 4B) protein expression in pregnant mice were significantly increased by approximately 50\% compared with nonpregnant mice. Pregnancy did not significantly affect protein expression of Ugt1a6, Ugt1a8, Ugt1a10, and Ugt2b35 (Fig. 4, C-F).

The yield of total membrane protein isolation and liver weight may be altered by pregnancy, affecting the total amount of Ugts in the whole liver. The yield of total membrane protein isolation from mouse liver was $0.08 \pm 0.01$ and $0.10 \pm 0.02 \mu \mathrm{g} / 1 \mathrm{mg}$ of liver tissue for nonpregnant and pregnant mice, respectively. The liver weight was $1.3 \pm 0.1$ and $2.1 \pm 0.1 \mathrm{~g}$ for nonpregnant and pregnant mice, respectively. After scaling the data of Fig. 4 to the whole liver, the protein levels of Ugt1a1, Ugt1a10, Ugt2b1, and Ugt2b35 were significantly induced approximately 2- to 2.5 -fold by pregnancy (Fig. 5, A-D). Pregnancy did not significantly affect the protein levels of Ugt1a6 and Ugtla8 in the whole liver (Fig. 5, E and F).

\section{Discussion}

The present study demonstrates that pregnancy significantly increases the systemic clearance of NBUP in a mouse model, which could be due to pregnancy-induced changes in factors important for NBUP disposition such as enhanced biliary excretion, induced hepatic metabolism, decreased plasma protein binding, or increased renal excretion. NBUP is a substrate of the efflux transporter P-glycoprotein and Ugts in the liver and can be cleared by the kidney (Kacinko et al., 2009; Brown et al., 2012; Liao et al., 2017). To date, there has been no evidence suggesting that pregnancy induces P-glycoprotein in the liver. The contribution of altered plasma protein binding can be ruled out as we showed that pregnancy did not significantly change plasma protein binding of NBUP in mice. Thus, the increase in NBUP clearance could be due to the combination of increased Ugt-mediated hepatic metabolism and

TABLE 2

The maternal plasma exposure (AUC), systemic clearance (CL), and plasma fraction unbound $\left(\mathrm{f}_{\mathrm{u}}\right)$ of norbuprenorphine (NBUP) and norbuprenorphine-3- $\beta$-D-glucuronide (NBUP-G) in pregnant and nonpregnant mice

Data shown are means (95\% confidence interval). The NBUP-G/NBUP plasma AUC ratios were calculated based on molar concentrations of NBUP and NBUP-G in the maternal plasma. Differences between the pharmacokinetic parameters were calculated by the nonparametric bootstrap method as described in Materials and Methods. Differences in the PK parameters between pregnant and nonpregnant mice with $P$ values of $<0.05$ were considered statistically significant.

\begin{tabular}{lcrr}
\hline PK Parameter & Pregnant & Nonpregnant & $P$ \\
\hline AUC $_{0-\infty}$ of NBUP $\left(\mu \mathrm{g} \times \mathrm{min} \times \mathrm{ml}^{-1}\right)$ & $4.2(3.0,6.5)$ & $10.8(6.0,16.1)$ & $<0.05$ \\
$\mathrm{AUC}_{0-\infty}$ of NBUP $(\mu \mathrm{M} \times \mathrm{min})$ & $10.2(7.3,15.7)$ & $26.1(14.5,38.9)$ & $<0.05$ \\
$\mathrm{CL}$ of NBUP $\left(\mathrm{ml} \times \mathrm{min}^{-1}\right)$ & $7.8(5.1,10.7)$ & $3.1(2.0,5.5)$ & $<0.05$ \\
$\mathrm{AUC}_{0-\infty}$ of NBUP-G $\left(\mu \mathrm{g} \times \mathrm{min} \times \mathrm{ml}^{-1}\right)$ & $27.9(23.0,40.8)$ & $66.2(43.2,101.5)$ & $<0.05$ \\
$\mathrm{AUC}_{0-\infty}$ of NBUP-G $(\mu \mathrm{M} \times \mathrm{min})$ & $57.0(47.0,83.3)$ & $135.2(88.2,207.3)$ & $<0.05$ \\
NBUP-G/NBUP plasma AUC Ratio $_{\mathrm{f}_{\mathrm{u}} \text { of NBUP }(\%)}^{5.6(5.3,6.5)}$ & $5.2(5.0,6.0)$ & $>0.05$ \\
\hline
\end{tabular}



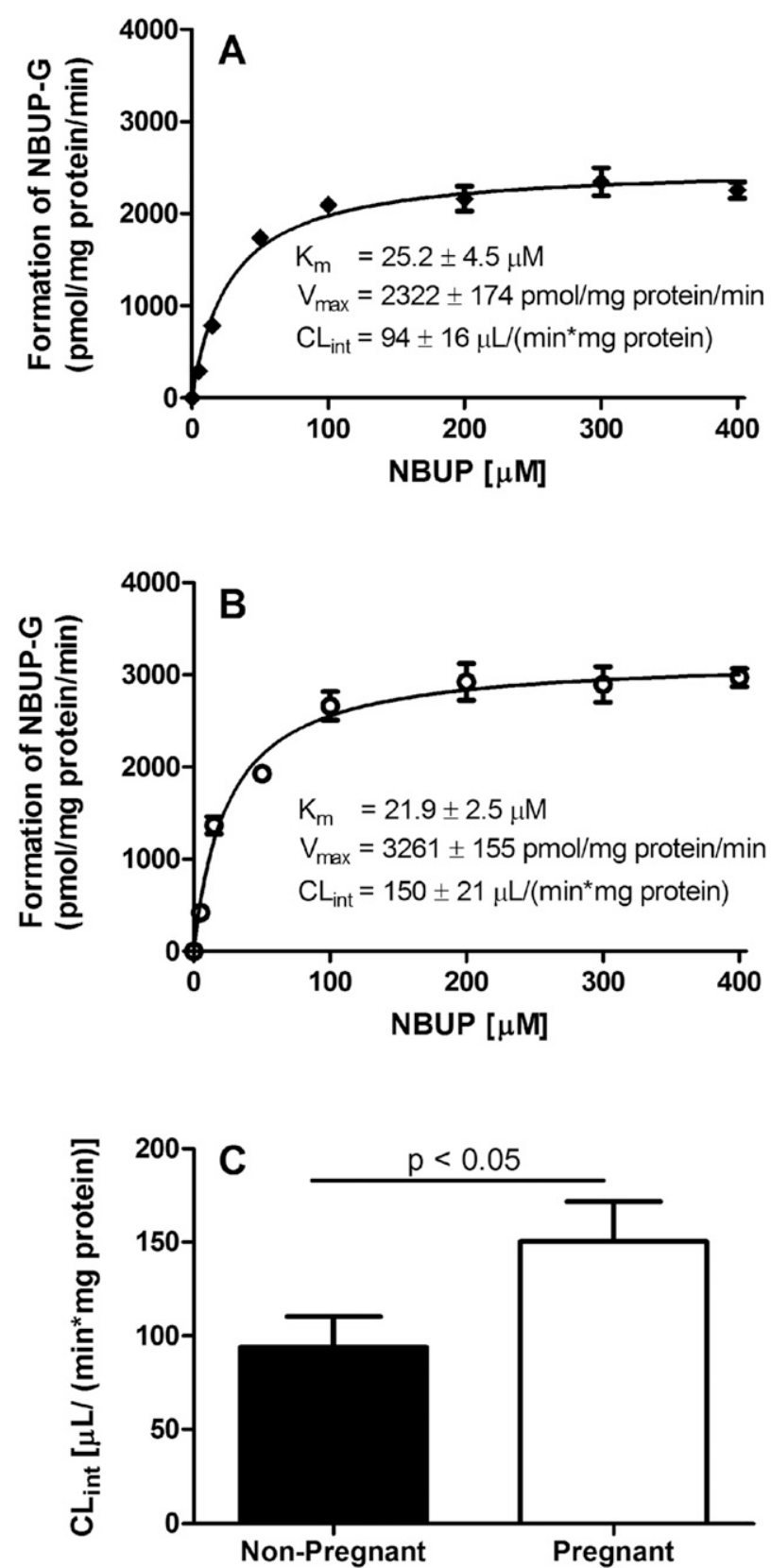

Fig. 3. Norbuprenorphine-3- $\beta$-D-glucuronide (NBUP-G) formation kinetics in mouse liver microsomes isolated from pregnant and nonpregnant mice. A representative NBUP-G formation kinetic profile over substrate (NBUP) concentrations up to $400 \mu \mathrm{M}$ in mouse liver microsomes isolated from nonpregnant and pregnant mice is shown in (A and B), respectively. Shown are means of S.D. of a representative kinetic experiment with triplicate determinations at each substrate concentration. The kinetic experiments were repeated independently three times, each with triplicate determinations at each substrate concentration, and similar results were obtained. The $K_{\mathrm{m}}, V_{\max }, \mathrm{CL}_{\text {int }}$ were calculated with all experimental data obtained. (C) $\mathrm{CL}_{\text {int }}$ of NBUP-G formation in pregnant (open bar) and nonpregnant (filled bar) mice. Statistically significant differences between pregnant and nonpregnant mice were analyzed by Student's $t$ test, with $P$ values of $<0.05$.

increased renal excretion. Kacinko et al. (2009) showed that the amount of NBUP-G excreted in urine was six times the amount of NBUP after administration of BUP and the cumulative NBUP excreted in urine was minimal, suggesting that renal clearance of NBUP plays a minor role in the overall disposition of NBUP. However, since pregnancy is known to increase renal clearance of drugs (Jeyabalan and Conrad, 2007), increased renal clearance of NBUP in pregnant mice versus nonpregnant mice cannot be ruled out. On the other hand, the data of NBUP-G formation in mouse liver microsomes suggest that induction of Ugtmediated hepatic metabolism of NBUP is likely the primary cause of the increased systemic CL of NBUP during pregnancy. We did perform in vitro-to-in vivo scaling in an attempt to predict in vivo intrinsic CL of NBUP based on the in vitro microsomal $\mathrm{CL}_{\text {int }}$ of NBUP (data not shown). Consistent with literature data (Mistry and Houston, 1987; Boase and Miners, 2002), the Ugt-mediated $\mathrm{CL}_{\text {int }}$ of NBUP from microsome incubations underpredicted the in vivo intrinsic CL by nearly 20 -fold. Reasons for the underprediction have been well documented. It is conceivable that the drug entry into the alamethicin-permeabilized membrane active sites is different from in vivo microenvironment. Other confounders include nonspecific binding, inappropriate kinetic modeling, and failure to account for transporters and extrahepatic metabolism.

UGT1A1 and UGT1A4 play a major role in metabolizing labetalol (McNeil and Louis, 1984) and lamotrigine (Gulcebi et al., 2011), respectively. BUP is a substrate of UGT1A1, UGT1A3, UGT2B7, and UGT2B17 (Picard et al., 2005; Chang and Moody, 2009; Rouguieg et al., 2010). Our results are in line with clinical studies showing that the apparent oral clearance of these medications is significantly increased during pregnancy compared with postpartum or nonpregnant women (Ohman et al., 2000; Fischer et al., 2014; Bastian et al., 2017). An increase in the clearance of drugs can significantly decrease systemic drug concentrations and may lead to suboptimal therapeutic outcomes. It is thus critical to investigate if the increase in the clearance of these drugs during pregnancy is due to induction of UGT-mediated hepatic metabolism. Results of this study suggest that the mouse model could possibly be suitable for such studies. Nevertheless, caution should be taken when extrapolating data from mice to humans due to the lack of sufficient knowledge about species differences in functions, expression, and tissue distribution of individual UGT/Ugt isoforms between humans and mice (Yang et al., 2017). Indeed, we showed in this study that the $K_{\mathrm{m}}$ values of NBUP-G formation by Ugts in mouse liver were six to seven times lower than the $K_{\mathrm{m}}$ of human UGTs reported in a previous study (Chang and Moody, 2009).

We found that protein expression of Ugtla1 and Ugt2b1 in total membrane proteins isolated from the mouse liver was significantly induced by pregnancy (Fig. 4, A and B). Induction of protein expression of mouse Ugts by pregnancy is consistent with mouse liver microsome incubation analysis that showed that pregnancy did not affect the $K_{\mathrm{m}}$ of NBUP-G formation but significantly increased the $V_{\max }$. It has been shown that that $17 \beta$-estradiol may upregulate human UGT1A4 via the estrogen receptor $\alpha$ (Chen et al., 2009) and that progesterone induces human UGT1A1 (Jeong et al., 2008) possibly through the pregnane-Xreceptor (Chen et al., 2012). Whether other human UGT isoforms including UGT1A3, UGT2B7, and UGT2B17 could be induced by the pregnancy-related hormones is not known. The induction of UGT1A expression by pregnancy-specific hormones is in line with our protein quantification data. However, our protein quantification data are not consistent with other published studies for murine Ugtla1 (Chen et al., 2012; Wen et al., 2013). Wen et al. (2013) demonstrated that on gestation day 14, hepatic protein expression of Ugtla1 in pregnant mice determined by immunoblotting was not significantly altered compared with that in nonpregnant mice. Chen et al. (2012) also showed by immunoblotting that hepatic Ugt 1a1 in mice was not induced by pregnancy. Changes in protein levels of Ugtla1 in the previous studies could possibly have gone unnoticed given the low selectivity and sensitivity of immunoblotting in detecting changes in protein expression compared with the highly sensitive LC-MS/MS technique used in this study.

We noted that protein levels of Ugt1a1 and Ugt2b1 in total membrane protein extracts shown in Fig. 4 were increased by $\sim 50 \%$ in pregnant 
A
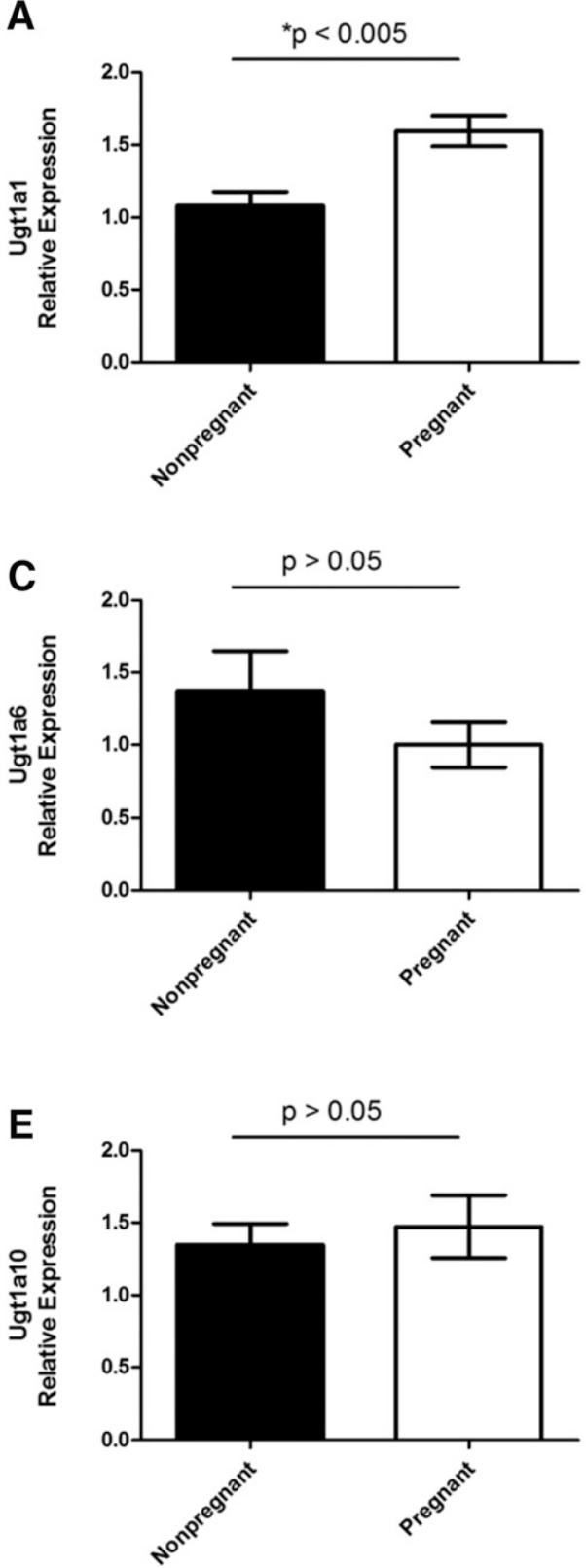

B

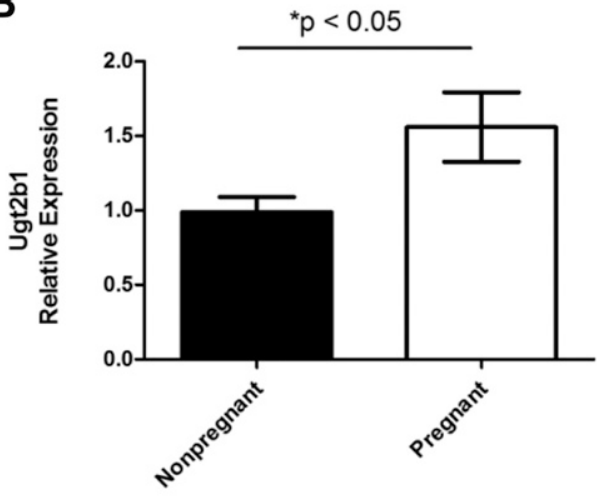

D

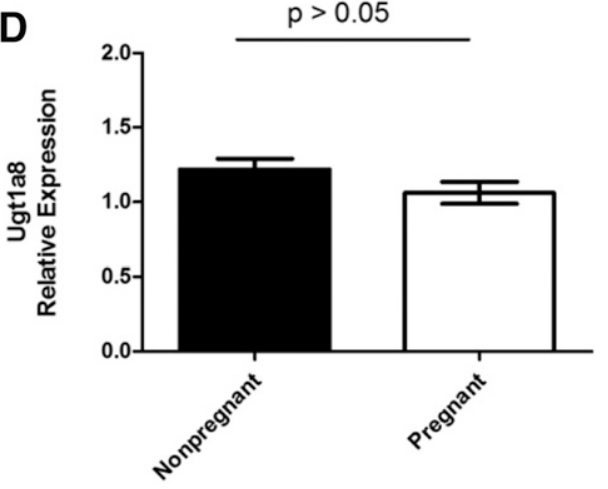

Fig. 4. Relative protein expression of Ugts in hepatic tissues of pregnant and nonpregnant mice. Relative protein expression of mouse Ugt1a1 (A), Ugt2b1 (B), Ugtla6 (C), Ugt1a8 (D), Ugt1a10 (E), Ugt2b35 (F) in isolated total membrane proteins of mouse livers from pregnant (open bars) and nonpregnant (filled bars) mice was quantified by LC-MS/MS. The protein expression levels were normalized to protein expression of respective Ugt in pooled tissue homogenates that were used as quality controls. Data shown are means \pm S.D. from three independent liver tissues per group. Statistically significant differences between pregnant and nonpregnant mice were analyzed by Student's $t$ test, with $P$ values of $<0.05$ (*).

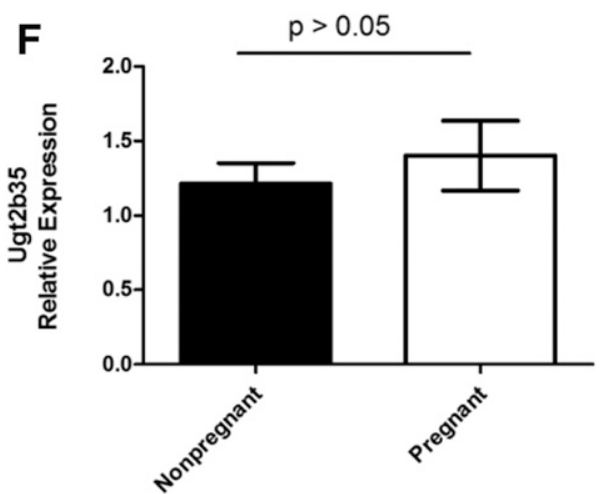

mice versus nonpregnant mice. This $50 \%$ increase cannot fully explain the twofold increase in the systemic CL of NBUP. We figured that the increase in Ugt protein levels in total membrane protein extracts do not fully reflect the changes in the amount of Ugts expressed in the whole liver due to concomitant increase in membrane protein content and liver weight during pregnancy. Indeed, after scaling to the whole liver with consideration of the yield of membrane protein isolation and the change in liver weight during pregnancy, we found that the whole liver content of Ugt1a1, Ugt1a10, Ugt2b1, and Ugt2b35 increased 2- to 2.5-fold by pregnancy (Fig. 5). It appears that the increase in hepatic Ugt content can now explain the 2 -fold increase in the systemic CL of NBUP in pregnant mice versus nonpregnant mice. It is important to note that although relative protein expression of some Ugts (Ugt1a10 and Ugt2b35) in total membrane proteins was not changed by pregnancy, the amount of protein of these Ugts in the whole liver were still significantly increased by pregnancy due to increase in protein content and liver weight in pregnant mice versus nonpregnant mice. This should be taken into account in interpretation of pregnancy-induced $P K$ changes for drugs metabolized by UGTs.

We showed that the plasma concentrations of NBUP-G were several times higher than those of NBUP over time in both pregnant and nonpregnant mice (Fig. 2), suggesting that the systemic clearance of NBUP is much faster than that of NBUP-G. Furthermore, although hepatic glucuronidation of NBUP is significantly induced by pregnancy, the $\mathrm{AUC}_{\text {metabolite }} / \mathrm{AUC}_{\text {parent }}$ ratio remained relatively unchanged in pregnant and nonpregnant mice (Table 2). The metabolite/parent AUC ratio is dependent on both the formation clearance $\left(\mathrm{CL}_{\mathrm{f}}\right)$ and elimination clearance of the metabolite $\left(\mathrm{CL}_{\mathrm{m}}\right)$. The relatively unchanged metabolite/parent AUC ratio indicates that the systemic elimination clearance of NBUP-G is increased in pregnant mice versus nonpregnant mice. The increased elimination clearance of NBUP-G in pregnant mice could be due to increased expression of Bcrp in mouse liver of pregnant mice compared with nonpregnant mice. We previously showed that protein levels of Bcrp in the mouse liver increase 3-fold in pregnant mice on gd 
A
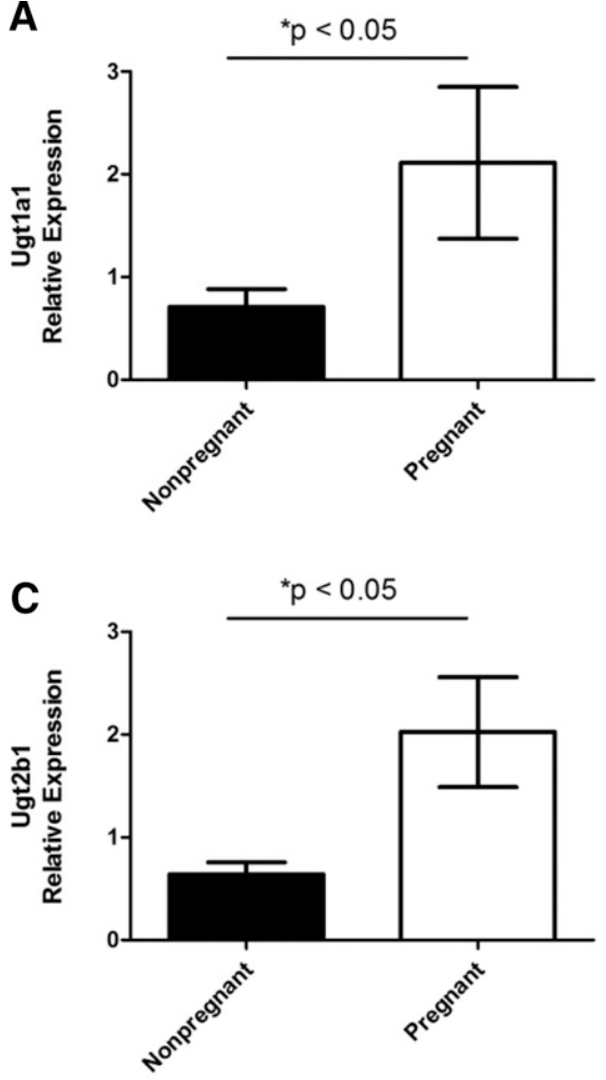

$\mathbf{E}$

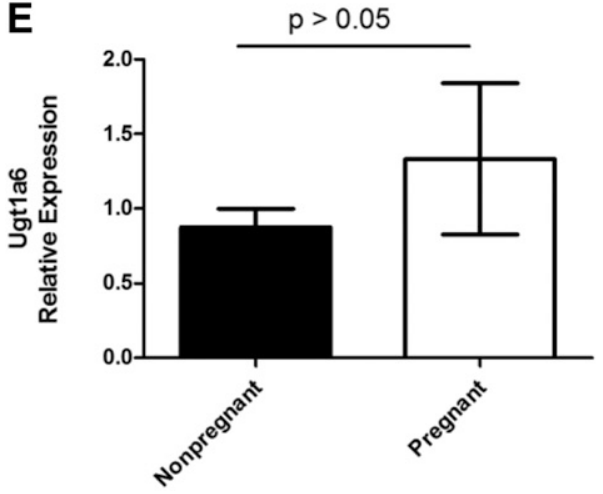

B
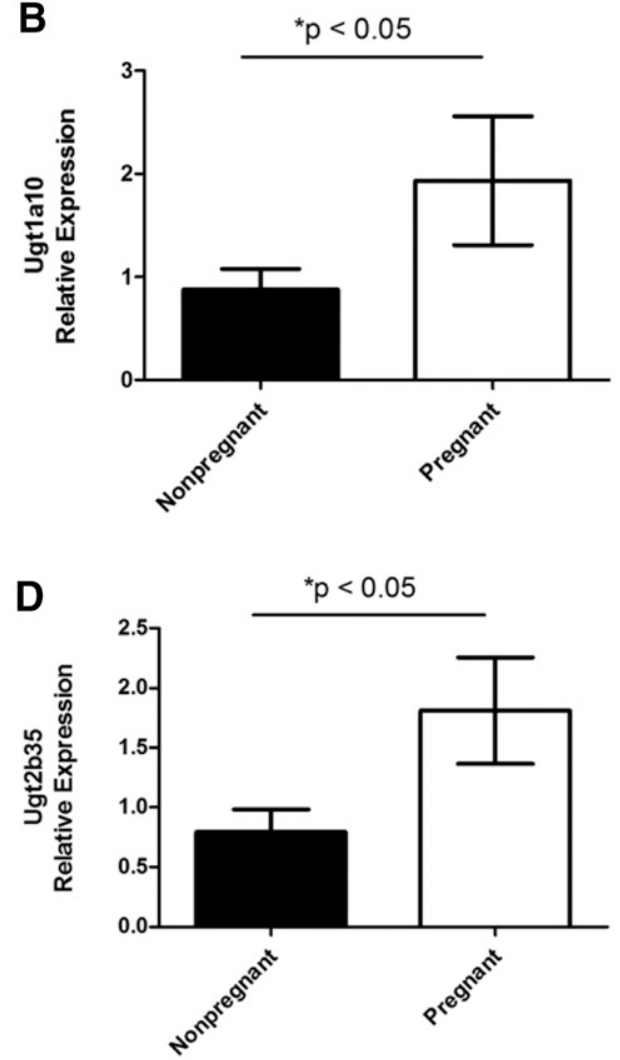

$\mathbf{F}$

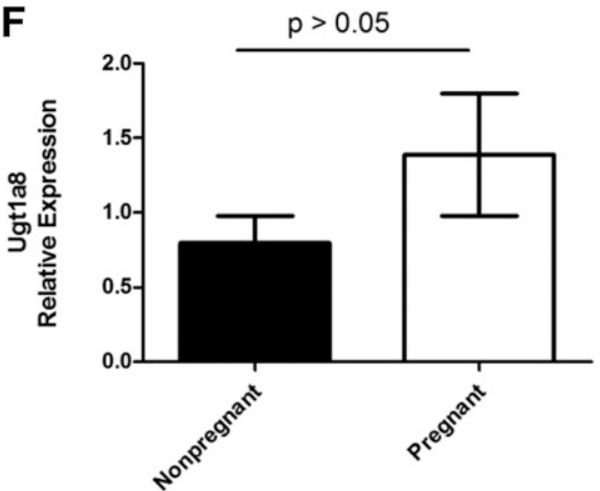

Fig. 5. Relative protein expression of Ugts in hepatic tissues of pregnant and nonpregnant mice after scaling to the whole liver. Relative protein expression of mouse Ugtla1 (A), Ugt2b1 (B), Ugt1a6 (C), Ugt1a8 (D), Ugt1a10 (E), Ugt2b35 (F) after scaling to the whole liver of pregnant (open bars) and nonpregnant (filled bars) mice. Data shown are means \pm S.D. from three independent liver tissues per group. Statistically significant differences between pregnant and nonpregnant mice were analyzed by Student's $t$ test, with $P$ values of $<0.05\left(^{*}\right)$.
15 versus nonpregnant mice (Wang et al., 2006). Our most recent study suggested that NBUP-G is likely a substrate of mouse Bcrp (Liao et al., 2017). Hence, biliary elimination of NBUP-G could be facilitated due to increased Bcrp expression in the liver of pregnant mice. NBUP-G is also partly eliminated via renal clearance (Kacinko et al., 2009). Studies have shown that glomerular filtration rate is increased by $50 \%$ during the first trimester and continues to increase throughout pregnancy (Jeyabalan and Conrad, 2007). Hence, an increase in glomerular filtration rate during pregnancy may also contribute to the increased elimination of NBUP-G in pregnant mice. We realize that, to fully explain the PK changes of NBUP-G, it is necessary to directly investigate the mechanisms and kinetics of NBUP-G clearance in mice. This would be a topic of investigation in future studies.

In summary, this study demonstrates that pregnancy induces total protein content of several Ugts in mice, leading to increased systemic clearance of NBUP. Our proteomic analysis revealed that hepatic Ugts are differentially regulated by pregnancy; in particular, Ugt1a1 and
Ugt2b1 were significantly induced. How such a change in NBUP disposition may affect overall disposition and hence the efficacy and safety of the parent BUP during pregnancy warrants further investigation. The plasma AUC of BUP has been shown to be significantly decreased during pregnancy (Bastian et al., 2017), and dose adjustments may be required to maintain efficacy in pregnant women. A major concern of such dose adjustments is the toxicity (e.g., respiratory depression) of the major circulating metabolite NBUP. Results of this study suggest that the toxicity of NBUP may be compensated by its increased clearance during pregnancy.

\section{Acknowledgments}

We gratefully thank Dr. Laura Shireman of the University of Washington Pharmacokinetics and Modeling Laboratory, Prachi Jha of Dr. Prasad's laboratory, and W. Katherine Tan of the University of Washington Department of Biostatistics for R programing, mass spectrometry analysis and biostatistics consultation, respectively. We also thank members of the University of 
Washington Pharmacokinetics of Drugs of Abuse during Pregnancy (PK-DAP) program for discussions.

\section{Authorship Contributions}

Participated in research design: Liao, Mao.

Conducted experiments: Liao, Gao, Bhatt, Neradugomma, Han.

Contributed new reagents or analysis tools: Phillips, Shen, Bhatt, Prasad.

Performed data analysis: Liao, Bhatt.

Wrote or contributed to the writing of the manuscript: Liao, Prasad, Shen, Mao.

\section{References}

Anderson GD (2005) Pregnancy-induced changes in pharmacokinetics: a mechanistic-based approach. Clin Pharmacokinet 44:989-1008.

Bastian JR, Chen H, Zhang H, Rothenberger S, Tarter R, English D, Venkataramanan R, and Caritis SN (2017). Dose-adjusted plasma concentrations of sublingual buprenorphine are lower during than after pregnancy. Am J Obstet Gynecol 216:64 e1-64 e7.

Boase S and Miners JO (2002) In vitro-in vivo correlations for drugs eliminated by glucuronidation: investigations with the model substrate zidovudine. Br J Clin Pharmacol 54:493-503.

Boberg M, Vrana M, Mehrotra A, Pearce RE, Gaedigk A, Bhatt DK, Leeder JS, and Prasad B (2017) Age-dependent absolute abundance of hepatic carboxylesterases (CES1 and CES2) by LC-MS/MS proteomics: application to PBPK modeling of oseltamivir in vivo pharmacokinetics in infants. Drug Metab Dispos 45:216-223.

Brown SM, Campbell SD, Crafford A, Regina KJ, Holtzman MJ, and Kharasch ED (2012) P-glycoprotein is a major determinant of norbuprenorphine brain exposure and antinociception. $J$ Pharmacol Exp Ther 343:53-61.

Brown SM, Holtzman M, Kim T, and Kharasch ED (2011) Buprenorphine metabolites, buprenorphine-3-glucuronide and norbuprenorphine-3-glucuronide, are biologically active. Anesthesiology 115:1251-1260.

Buckley DB and Klaassen CD (2007) Tissue- and gender-specific mRNA expression of UDPglucuronosyltransferases (UGTs) in mice. Drug Metab Dispos 35:121-127.

Chang Y and Moody DE (2009) Glucuronidation of buprenorphine and norbuprenorphine by human liver microsomes and UDP-glucuronosyltransferases. Drug Metab Lett 3 101-107.

Chen H, Yang K, Choi S, Fischer JH, and Jeong H (2009) Up-regulation of UDPglucuronosyltransferase (UGT) 1A4 by 17beta-estradiol: a potential mechanism of increased lamotrigine elimination in pregnancy. Drug Metab Dispos 37:1841-1847.

Chen S, Yueh MF, Evans RM, and Tukey RH (2012) Pregnane-x-receptor controls hepatic glucuronidation during pregnancy and neonatal development in humanized UGT1 mice. Hepatology 56:658-667.

Chiang CN and Hawks RL (2003) Pharmacokinetics of the combination tablet of buprenorphine and naloxone. Drug Alcohol Depend 70 (2 Suppl):S39-S47.

Concheiro M, Jones HE, Johnson RE, Choo R, and Huestis MA (2011) Preliminary buprenorphine sublingual tablet pharmacokinetic data in plasma, oral fluid, and sweat during treatment of opioid-dependent pregnant women. Ther Drug Monit 33:619-626.

Fischer JH, Sarto GE, Hardman J, Endres L, Jenkins TM, Kilpatrick SJ, Jeong H, Geller S, Deyo K, Fischer PA, et al. (2014) Influence of gestational age and body weight on the pharmacokinetics of labetalol in pregnancy. Clin Pharmacokinet 53:373-383.

Gulcebi MI, Ozkaynakcı A, Goren MZ, Aker RG, Ozkara C, and Onat FY (2011) The relationship between UGT1A4 polymorphism and serum concentration of lamotrigine in patients with epilepsy. Epilepsy Res 95:1-8.

Hand CW, Sear JW, Uppington J, Ball MJ, McQuay HJ, and Moore RA (1990) Buprenorphine disposition in patients with renal impairment: single and continuous dosing, with special reference to metabolites. Br J Anaesth 64:276-282.

Jeong H, Choi S, Song JW, Chen H, and Fischer JH (2008) Regulation of UDPglucuronosyltransferase (UGT) $1 \mathrm{~A} 1$ by progesterone and its impact on labetalol elimination. Xenobiotica 38:62-75.

Jeyabalan A and Conrad KP (2007). Renal function during normal pregnancy and preeclampsia. Front Biosci 12, 2425-2437.

Jones HE, Kaltenbach K, Heil SH, Stine SM, Coyle MG, Arria AM, O'Grady KE, Selby P, Martin PR, and Fischer G (2010) Neonatal abstinence syndrome after methadone or buprenorphine exposure. $N$ Engl J Med 363:2320-2331.

Jones RT and Mendelson J (1997). Determination of buprenorphine mass balance. NIDA Contract N01DA-4-8306 Report, Pharmacokinetic and Pharmacodynamic Studies for Medication Development, NIDA.
Kacinko SL, Jones HE, Johnson RE, Choo RE, Concheiro-Guisan M, and Huestis MA (2009) Urinary excretion of buprenorphine, norbuprenorphine, buprenorphine-glucuronide, and norbuprenorphine-glucuronide in pregnant women receiving buprenorphine maintenance treatment. Clin Chem 55:1177-1187.

Kacinko SL, Jones HE, Johnson RE, Choo RE, and Huestis MA (2008) Correlations of materna buprenorphine dose, buprenorphine, and metabolite concentrations in meconium with neonatal outcomes. Clin Pharmacol Ther 84:604-612.

Kim HK, Smiddy M, Hoffman RS, and Nelson LS (2012) Buprenorphine may not be as safe as you think: a pediatric fatality from unintentional exposure. Pediatrics 130:e1700-e1703.

Liao MZ, Gao C, Shireman LM, Phillips B, Risler LJ, Neradugomma NK, Choudhari P, Prasad B, Shen DD, and Mao Q (2017) P-gp/ABCB1 exerts differential impacts on brain and fetal exposure to norbuprenorphine. Pharmacol Res 119:61-71.

Mackenzie PI, Bock KW, Burchell B, Guillemette C, Ikushiro S, Iyanagi T, Miners JO, Owens IS, and Nebert DW (2005) Nomenclature update for the mammalian UDP glycosyltransferase (UGT) gene superfamily. Pharmacogenet Genomics 15:677-685.

Mager H and Göller G (1998) Resampling methods in sparse sampling situations in preclinical pharmacokinetic studies. J Pharm Sci 87:372-378.

Martin CE, Longinaker N, and Terplan M (2015) Recent trends in treatment admissions for prescription opioid abuse during pregnancy. J Subst Abuse Treat 48:37-42.

McCance-Katz EF, Moody DE, Smith PF, Morse GD, Friedland G, Pade P, Baker J, Alvanzo A, Jatlow P, and Rainey PM (2006) Interactions between buprenorphine and antiretrovirals. II. The protease inhibitors nelfinavir, lopinavir/ritonavir, and ritonavir. Clin Infect Dis $\mathbf{4 3}$ (Suppl 4): S235-S246.

McNeil JJ and Louis WJ (1984) Clinical pharmacokinetics of labetalol. Clin Pharmacokinet 9: $157-167$.

Mistry M and Houston JB (1987) Glucuronidation in vitro and in vivo. Comparison of intestinal and hepatic conjugation of morphine, naloxone, and buprenorphine. Drug Metab Dispos 15: $710-717$.

Ohman I, Vitols S, and Tomson T (2000) Lamotrigine in pregnancy: pharmacokinetics during delivery, in the neonate, and during lactation. Epilepsia 41:709-713.

Ohtani M, Kotaki H, Uchino K, Sawada Y, and Iga T (1994) Pharmacokinetic analysis of enterohepatic circulation of buprenorphine and its active metabolite, norbuprenorphine, in rats. Drug Metab Dispos 22:2-7.

Picard N, Cresteil T, Djebli N, and Marquet P (2005) In vitro metabolism study of buprenorphine: evidence for new metabolic pathways. Drug Metab Dispos 33:689-695.

Prasad B, Evers R, Gupta A, Hop CECA, Salphati L, Shukla S, Ambudkar SV, and Unadkat JD (2014) Interindividual variability in hepatic organic anion-transporting polypeptides and P-glycoprotein (ABCB1) protein expression: quantification by liquid chromatography tandem mass spectroscopy and influence of genotype, age, and sex. Drug Metab Dispos 42:78-88.

Rouguieg K, Picard N, Sauvage FL, Gaulier JM, and Marquet P (2010) Contribution of the different UDP-glucuronosyltransferase (UGT) isoforms to buprenorphine and norbuprenorphine metabolism and relationship with the main UGT polymorphisms in a bank of human liver microsomes. Drug Metab Dispos 38:40-45.

Shuster DL, Risler LJ, Liang CK, Rice KM, Shen DD, Hebert MF, Thummel KE, and Mao Q (2014) Maternal-fetal disposition of glyburide in pregnant mice is dependent on gestational age. J Pharmacol Exp Ther 350:425-434.

Stotts AL, Dodrill CL, and Kosten TR (2009) Opioid dependence treatment: options in pharmacotherapy. Expert Opin Pharmacother 10:1727-1740.

U.S. Food and Drug Administration (2016). Guidance for Industry: Safety Testing of Drug Metabolites, FDA, Silver Spring, MD.

Wang H, Wu X, Hudkins K, Mikheev A, Zhang H, Gupta A, Unadkat JD, and Mao Q (2006) Expression of the breast cancer resistance protein (Bcrp1/Abcg2) in tissues from pregnant mice: effects of pregnancy and correlations with nuclear receptors. Am J Physiol Endocrinol Metab 291:E1295-E1304.

Wen X, Donepudi AC, Thomas PE, Slitt AL, King RS, and Aleksunes LM (2013) Regulation of hepatic phase II metabolism in pregnant mice. J Pharmacol Exp Ther 344:244-252.

Yang N, Sun R, Liao X, Aa J, and Wang G (2017) UDP-glucuronosyltransferases (UGTs) and their related metabolic cross-talk with internal homeostasis: a systematic review of UGT isoforms for precision medicine. Pharmacol Res 121:169-183.

Yassen A, Kan J, Olofsen E, Suidgeest E, Dahan A, and Danhof M (2007) Pharmacokineticpharmacodynamic modeling of the respiratory depressant effect of norbuprenorphine in rats. J Pharmacol Exp Ther 321:598-607.

Address correspondence to: Dr. Qingcheng Mao, Department of Pharmaceutics, University of Washington, Box 357610, Room 272F, Health Science Bldg., Seattle, WA 98195. E-mail: qmao@u.washington.edu 